\title{
INDIRECT PULP TREATMENT IN A PERMANENT MOLAR: CASE REPORT OF 4-YEAR FOLLOW-UP
}

\author{
Ticiane Cestari FAGUNDES ${ }^{1}$, Terezinha Jesus Esteves BARATA ${ }^{2}$, Anuradha PRAKKI ${ }^{3}$, \\ Eduardo BRESCIANI ${ }^{4}$, José Carlos PEREIRA ${ }^{5}$
}

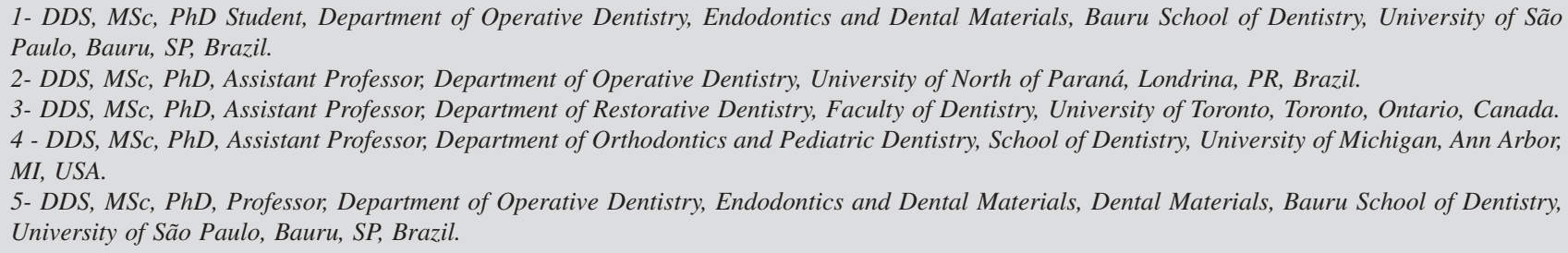

Corresponding address: Ticiane Cestari Fagundes - Faculdade de Odontologia de Bauru - Universidade de São Paulo - Alameda Dr. Octávio Pinheiro Brisolla, 9-75 - 17.012-101- Bauru, SP - Brasil - Phone: + 55-18-9706-7998 - Fax: +55-14- 3224-1388 - e-mail: ticifag@usp.br

Received: May 20, 2008 - Modification: August 31, 2008 - Accepted: September 15, 2008

\begin{abstract}
$T_{\mathrm{h}}$ reported reported discomfort associated with thermal stimulation on the permanent mandibular left first molar. The radiographs revealed a deep distal caries lesion, very close to the pulp, absence of radiolucencies in the periapical region, and absence of periodontal space thickening. Pulp sensitivity was confirmed by thermal pulp vitality tests. Based on the main complaint and the clinical and radiographic examinations, the treatment plan was established to preserve pulp vitality. Clinical procedures consisted of removing the infected dentin and lining the caries-affected dentin with calcium hydroxide paste. The tooth was provisionally sealed for approximately 60 days. After this period, tooth vitality was confirmed, the remaining carious dentin was removed, and the tooth was restored. At 4year follow-up, no clinical or radiographic pathological findings were found.
\end{abstract}

Key words: Dental Caries. Dental pulp. Biocompatible materials. Dental restoration.

\section{INTRODUCTION}

Concepts and treatment principles of deep caries lesion are an area of debate and constant change ${ }^{5}$. Difficulties in assessing the true clinical status of the pulp tissue under deep caries lesion make difficult a precise diagnosis of tooth vitality ${ }^{4}$. An important priority in the treatment of deep caries lesions is to preserve pulp vitality ${ }^{23}$. More conservative pulp management has the potential to reduce the need for a more invasive endodontic treatment ${ }^{3}$. A repair capacity of pulp tissue after removal of caries lesion without pulp exposure is expected to occur. However, after pulp exposure, such conservative treatment is questionable and unpredictable ${ }^{23}$. In addition, if pulp has become infected and exposed during caries removal, successful outcome will be substantially reduced $^{23}$. In such cases, in order to avoid pulp exposures, a conservative procedure has been suggested: the indirect pulp treatment (IPT). This treatment, which can be either an onestep or a two-step procedure, has also been denominated stepwise excavation $^{10,18,19}$.

IPT removes the infected dentin, leaving a thin layer of deeper affected dentin when complete caries lesion removal would result in pulp exposure. Stepwise excavation involves a step-by-step procedure at intervals ${ }^{17}$. Basically, the first step consists of partial dentin caries removal and cavity sealing with calcium hydroxide and a restorative material. After 8 to 12 weeks, which is a considered convenient period for pulp recovering, the second step is performed ${ }^{17}$. At this time, the remained caries lesion is removed and the tooth is conventionally restored. In the present article, a conservative approach used to maintain pulp vitality of a permanent tooth with deep caries lesion will be described.

\section{CASE REPORT}

A 16-year-old male patient scheduled for routine dental treatment reported discomfort associated with physical stimulation on the permanent mandibular left first molar. No history of spontaneous pulpal pain was reported. Status of the pulp and periradicular tissues was carefully evaluated. The clinical examination revealed normal appearance of 


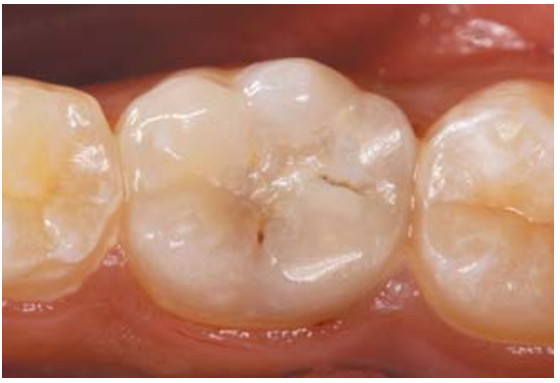

FIGURE 1- Permanent mandibular left first molar with small occlusal enamel caries lesion and slight color change

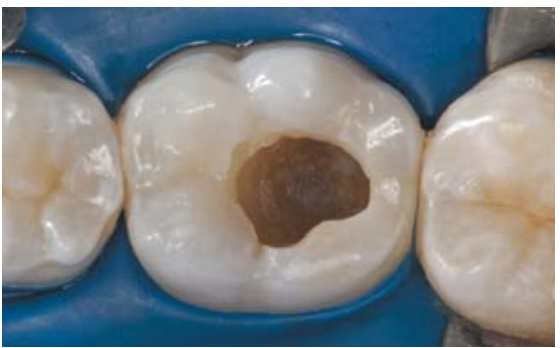

FIGURE 4- View of the cavity floor after removal of infected dentin

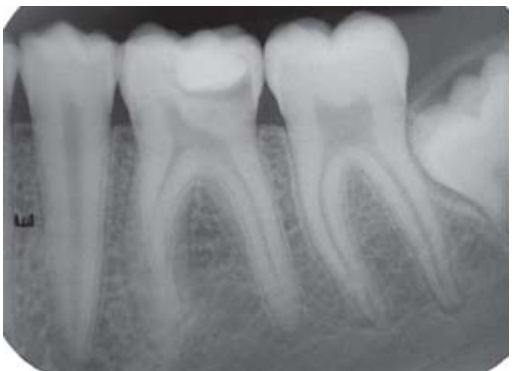

FIGURE 7- After 60 days, no signs of apical radiolucency or dentin resorption

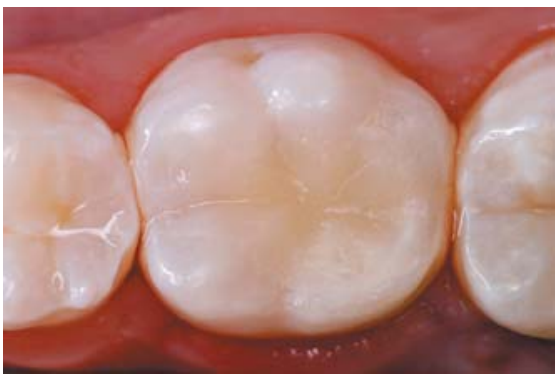

FIGURE 10- Occlusal view of the final restoration with adhesive/resin composite system

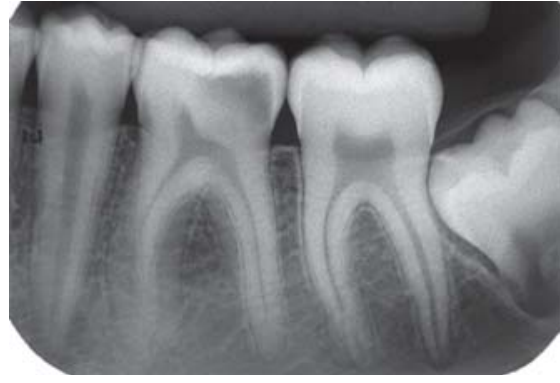

FIGURE 2 - Initial periapical radiograph showing deep caries lesion and norma periapical structures

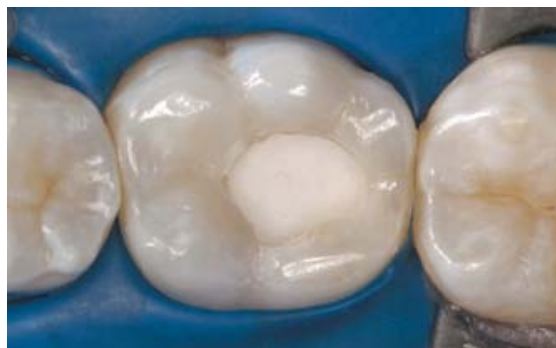

FIGURE 5- Dressing of cavity floor with calcium hydroxide paste directly over the affected dentin

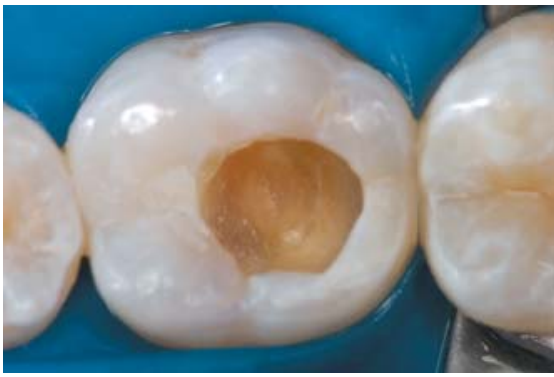

FIGURE 8- Recall aspect of the dry remained dentin on cavity floor, after 60 days

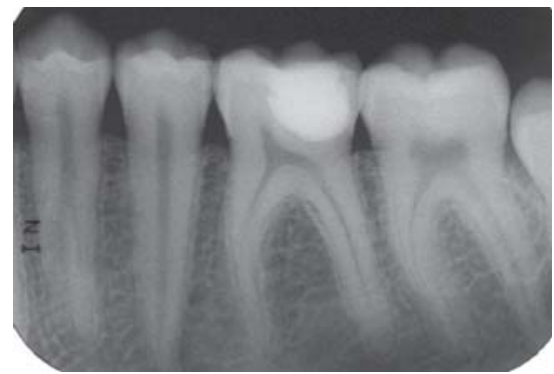

FIGURE 11- Radiograph showing sound tooth and periodontal structures after 4year follow-up

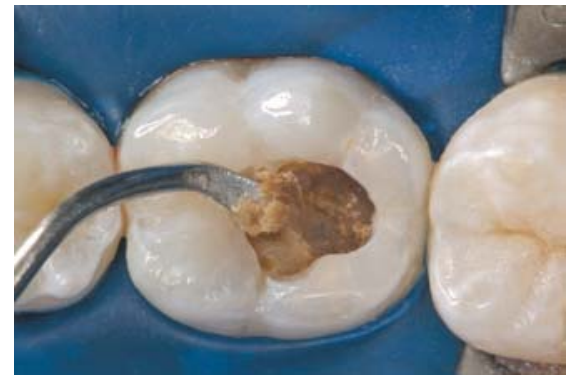

FIGURE 3- After cavity access, initial removal of soft carious dentin with excavator

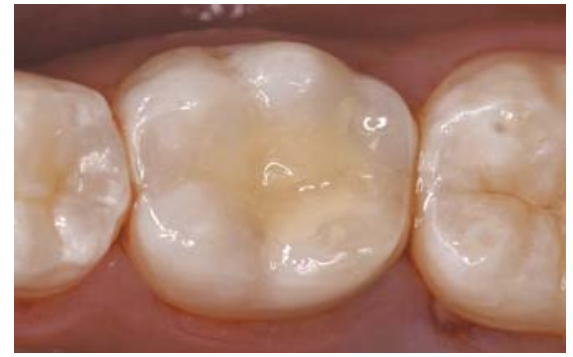

FIGURE 6- Temporary restoration with resin-modified glass-ionomer cement

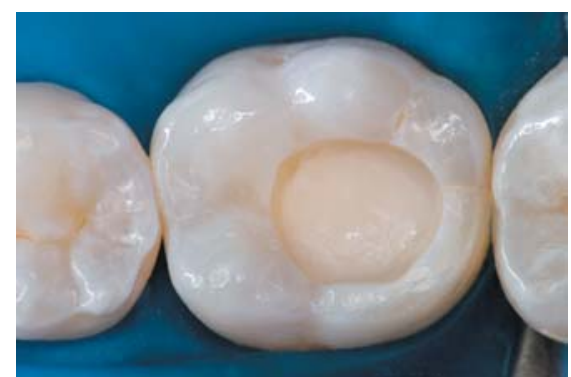

FIGURE 9- A resin-modified glassionomer cement base placed over a thin layer of calcium hydroxide cement

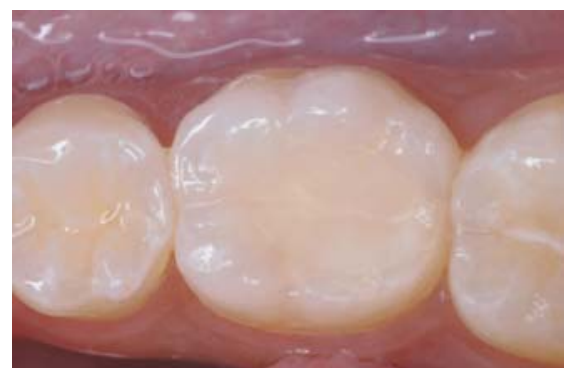

FIGURE 12- Occlusal view of the restoration after 4 years of follow-up 
TABLE 1- Indication to undertake the IPT procedure is based on the following findings ${ }^{1,10}$

1. History

2. Clinical Examination
a) discomfort associated to thermal stimulation
b) negative history of spontaneous pain

a) active caries lesion in deep dentin

b) absence of clinical diagnosis of pulp exposure, fistula, swelling of periodontal tissues, and abnormal tooth mobility

c) absence of clinical symptoms of irreversible pulpitis, such as spontaneous pain or sensitivity to pressure

c) normal appearance of adjacent gingiva

d) normal tooth color

a) absence of radiolucencies at the periapical regions, or thickening of the periodontal spaces, that would indicate the presence of irreversible pulp pathologies or necrosis

b) extension of the caries lesion should be such that complete caries removal would represent risk of pulp exposure adjacent gingival tissue and small enamel caries lesion. A slight color change was noticed through occlusal enamel (Figure 1). Bitewing radiograph revealed deep distal caries lesion. No radiolucencies at the periapical regions or thickness of the periodontal spaces were noticed in periapical radiograph (Figure 2). Pulp sensitivity compatible with reversible stage of inflammation was confirmed with thermal tests. Pain quickly disappeared after cold stimulus.

Indications of IPT are summarized in Table 1. The guidelines for the adopted two-step procedure were as follows ${ }^{26}$ :

\section{First step}

_Intervention started with the teeth prophylaxis with water and pumice, followed by local anesthesia. Operative field was then isolated with rubber dam.

\#4 diamond bur (KG Sorensen, São Paulo, SP, Brazil) at high-speed with air/water spray was used to remove enamel and to reach caries lesion. Infected dentin from cavity walls was firstly removed with a spoon excavator \#17 (Duflex-SS White, Rio de Janeiro, RJ, Brazil) followed by low-speed round carbide burs compatible with the size of the cavity. Care was taken to avoid pulp perforation. Excavation was performed carefully to remove only the wet carious dentin (Figure 3), leaving the dry demineralized affected dentin (Figure 4).

_Cavity was rinsed with calcium hydroxide and distilled water solution at $\mathrm{pH} 12$ (Merck, Darmstadt, Germany), and dried with sterilized cotton pellets. A dressing with calcium hydroxide and distilled water paste was placed directly over the affected dentin on the cavity floor (Figure 5). Excess of dressing material was removed from the surrounding cavity walls and enamel margins.

_Tooth was temporarily restored with resin-modified glass-ionomer cement (RMGIC) (Vitremer ${ }^{\mathrm{TM}}$, 3M/ESPE, St. Paul, MN, USA) mixed according to the manufacturer's instructions and applied with the aid of an injector syringe (Centrix, Shelton, CT, USA). Each layer was light-cured for $40 \mathrm{~s}$ with a light-curing unit (Astralis, Ivoclar Vivadent, Schaan, Liechtenstein). After rubber dam removal, occlusion was checked to prevent occlusion stress (Figure 6).

\section{Second step}

After 60 days, new clinical and radiographic records of tooth condition were performed. No spontaneous pain was reported during this period and the response to cold and hot stimuli was consistent with a normal vital pulp. No signs of apical radiolucency or dentin resorption were detected (Figure 7).

After local anesthesia, tooth was re-opened for complete removal of the remaining non-remineralized carious affected dentin with excavator and round carbide burs at low speed, thus avoiding pulp exposure (Figure 8).

Cavity was rinsed with calcium hydroxide solution, dried with sterilized cotton pellets and lined with calcium hydroxide cement, followed by application of RMGIC base (Vitrebond $^{\mathrm{TM}}$, 3M/ESPE) (Figure 9).

$35 \%$ phosphoric acid gel was applied for $30 \mathrm{~s}$ (Scotchbond $^{\mathrm{TM}}$ Etchant, 3M/ESPE), rinsed and dried with absorbent paper. Bonding agent was applied (Single Bond ${ }^{\mathrm{TM}}$, $3 \mathrm{M} / \mathrm{ESPE}$ ) and polymerized according to the manufacturer's instructions. Resin composite (Filtek Z250 ${ }^{\mathrm{TM}}$, A2 shade, 3M/ ESPE) was inserted using incremental technique. Each increment was polymerized for $40 \mathrm{~s}$. After rubber dam removal, occlusion was checked (Figure 10).

\section{Follow-up}

After 4 years, clinical and radiographic examinations were consistent with a normal vital pulp (Figures 11 and 12).

\section{DISCUSSION}

The choice for IPT in this case was based on careful pulp diagnosis, which was supported by evaluation of the 
history of pain, symptoms and clinical/radiographic findings. In the present case, positive results suggest IPT for management of deep caries lesion in permanent molars teeth. Most studies reported in the literature evaluated IPT for treatment of deep caries lesion in primary molars ${ }^{1,12,14,16,21,27,30}$ while some clinical studies were carried out on the permanent teeth $^{18-20,25}$. Retrospective and prospective studies showed that in both dentitions the success rate for IPT is similar, ranging from $73 \%$ to $95 \%$ after 2 weeks to 11 years of followup $^{1,12,14,16,18-21,25,27,30}$. Due to the lack of studies evaluating permanent teeth, the discussion presented here is also based on studies with primary teeth.

Active caries lesion can be distinguished into two layers: infected dentin which is a superficial soft layer of collagen fibrils partially degraded that cannot be remineralized; and affected dentin, which is partially demineralized, with intact collagen fibrils that can be remineralized ${ }^{22}$. However, the clinical recognition of these two layers is a difficult task because not only color and consistency of the dentin are absolute indicators of decayed tissue ${ }^{6}$. Experience and clinical judgment are essential skills for appropriate removal of infected dentin, leaving the potentially remineralizable affected dentin. For some authors it is not necessary the complete removal of decay in a second ste $\mathrm{p}^{14,28}$. Their clinical and radiographic results support the theory that the decay process was apparently arrested after IPT with a single visit procedure ${ }^{14}$. According to Fairbourn, et al. ${ }^{11}$, the second appointment may not be necessary, if the final restoration maintains the cavity sealed and the tooth asymptomatic. On the other hand, Leksell, et al. ${ }^{18}$ observed a statistically significant difference in the frequency of pulp exposures between one-step and two-step procedures. Furthermore, when the cavity is re-opened the clinician can inspect the cavity floor.

Patients' age is another factor to be considered since conservative treatments have been more indicated for young patients ${ }^{16}$. In this study, the patient treated was 16 years old. It is known that there is a reduction of the cell population, the pulpal volume, and also the vascular supply with the increase of pulp age ${ }^{29}$.

The material of choice to be placed over the demineralized dentin is another issue of discussion in the literature. Some materials that have bacteriostatic/ bactericidal effect were indicated for application over the affected dentin, such as: calcium hydroxide ${ }^{1,11,13,15,18,19,24,31}$, zinc-oxide eugenol (ZOE) cements ${ }^{7,11}$, dentin bonding agents $^{12,28}$ and glass ionomer cements (GIC) $)^{1,14,19,30,32}$.

Washing the cavity with calcium hydroxide solution is an important step for IPT because carious/demineralized dentin is left after the first visit. The use of calcium hydroxide solution has demonstrated to arrest caries lesion by its action on bacterial activity and growth ${ }^{15}$. As the carious tissue is not completely removed, the availability of calcium and hydroxyl ions is also important for subsequent remineralization and healing of the affected dentin. In the second visit, the solution of calcium hydroxide is useful to maintain a high $\mathrm{pH}$ value ${ }^{13}$, since metalloproteinases (MMPs) may be activated by an acidic $\mathrm{pH}$ brought by lactate release from cariogenic bacteria ${ }^{8}$.

The success rates of IPT in deep caries using calcium hydroxide liner varied from $92 \%$ to $97 \% 17^{1,18,19,30}$. It has been shown that the IPT with calcium hydroxide and a subsequent good marginal sealing reduced the substrate for bacteria, decreased lesion progression and promoted a physiological reaction in the pulp-dentin complex ${ }^{19}$. It was also observed that calcium hydroxide may induce sclerosis and formation of secondary dentin ${ }^{19,31}$. Possible explanations for these observations are the increase in the mineral content of the underlying dentin, as well as a chemical effect of calcium hydroxide on the soft demineralized dentin ${ }^{18}$.

ZOE cements can also be used as IPT agents and usually present high degrees of success ${ }^{11,18}$. These materials have been placed over the remaining carious dentin once their bactericidal properties and sealing qualities would result in inhibition of bacterial growth, arresting the carious process ${ }^{11}$.

Regarding the use of bonding agents, Ribeiro, et al. ${ }^{28}$ reported an altered hybrid layer without any signs of subsequent demineralization that could suggest progression of the lesion in primary molars when Scotchbond MultiPurpose adhesive system was used on carious dentin. These results were corroborated by another study that observed, also in primary teeth, the clinical success of IPT regardless of the application of calcium hydroxide prior to restoration with a composite resin ${ }^{12}$. This study suggest that, once the grossly decayed dentin is removed and good interfacial seal is provided, the healing process of the dentin-complex is independent from the application of an inducer of mineralization such as calcium hydroxide ${ }^{12}$. According to Cavalcanti, et al. ${ }^{7}$, adhesive systems release cytotoxic substances for human dental pulp fibroblasts in culture, whilst those leached from calcium hydroxide cement are biocompatible. Costa, et al. ${ }^{9}$ concluded that the total etching followed by application of One Step bonding agent cannot be recommended for deep cavities in permanent teeth. Future studies are necessary to evaluate the effect of both techniques (calcium hydroxide cement and dentin bonding agents) on bacterial growth in remaining affected dentin after IPT.

Vij, et al. ${ }^{30}$ reported a success rate of $92 \%$ after 2 years using GIC over deep caries in primary teeth, which is comparable to studies where calcium hydroxide liner was used $^{1,19,30}$. It has been suggested that success following caries control with GIC restorations may be due to the antimicrobial effect on streptococci mutans ${ }^{6}$. These cements have certain unique properties, such as the release of fluoride ions, coefficients of thermal expansion similar to those of tooth structure and biocompatibility ${ }^{32}$. Farooq, et al. ${ }^{14}$ reported $93 \%$ success of IPT in primary teeth with the use of a RMGIC as a liner without the use of calcium hydroxide over an average follow-up of 4 years.

In this case report, calcium hydroxide paste was applied followed by the placement of a RMCIC restoration. After 60 days, the restoration was changed for a calcium hydroxide cement liner, followed by application of a RMGIC base and placement of an adhesive restoration. At 4-year follow-up, neither clinical symptoms nor clinical and radiographic signs of pulp degeneration were found. The real role a liner with 
calcium hydroxide plays in IPT is not fully demonstrated, but the rate of success is high when this material is applied ${ }^{1,18,19,30}$. Further well designed randomized controlled trials are needed to investigate the potential of contemporary materials that may be suitable when used in the management of deep caries lesions ${ }^{23}$.

\section{CONCLUSION}

Based on the clinical and radiographic observations, it may be concluded that IPT maintained the pulp vitality and function of the permanent molar presented in this case report.

\section{REFERENCES}

1- Al-Zayer MA, Straffon LH, Feigal RJ, Welch KB. Indirect pulp treatment of primary posterior teeth: a retrospective study. Pediatr Dent. 2003;25(1):2936

2- Bjørndal L, Larsen T, Thylstrup A. A clinical and microbiological study of deep carious lesions during stepwise excavation using long treatment intervals. Caries Res. 1997;31(6):411-7.

3- Bjørndal L, Mjör IA. Pulp-dentin biology in restorative dentistry. Part 4: Dental Caries - characteristics of lesions and pulpal reactions. Quintessence Int. 2001;32(9):717-36

4- Bjørndal L. Dentin and pulp reactions to caries and operative treatment: biological variables affecting treatment outcome. Endod Topics. 2002;2(1):10-23.

5- Bjørndal L, Kidd EA. The treatment of deep dentine caries lesions. Dent Update. 2005;32(7):402-13

6- Bonecker M, Toi C, Cleaton-Jones P. Mutans streptococci and lactobacilli in carious dentine before and after Atraumatic Restorative Treatment. J Dent. 2003;31(6):423-8.

7- Cavalcanti BN, Rode SM, Marques MM. Cytotoxicity of substances leached or dissolved from pulp capping materials. Int Endod J. 2005;38(8):505-9.

8- Chaussain-Miller C, Fioretti F, Goldberg M, Menashi S. The role of matrix metalloproteinases (MMPs) in human caries. J Dent Res. 2006;85(1):22-32.

9- Costa CA, Giro EM, do Nascimento AB, Teixeira HM, Hebling J. Shortterm evaluation of the pulpo-dentin complex response to a resin-modified glass-ionomer cement and a bonding agent applied in deep cavities. Dent Mater. 2003;19(8):739-46.

10- Dumsha T, Hovland E. Considerations and treatment of direct and indirect pulp-capping. Dent Clin North Am. 1985;29(2):251-9.

11- Fairbourn DR, Charbeneau GT, Loesche WJ. Effect of improved Dycal and IRM on bacteria in deep carious lesions. J Am Dent Assoc. 1980;100(4):547-52.

12- Falster CA, Araujo FB, Straffon LH, Nör JE. Indirect pulp treatment: in vivo outcomes of an adhesive resin system vs calcium hydroxide for protection of the dentin-pulp complex. Pediatr Dent. 2002;24(3):241-8.

13- Farhad A, Mohammadi Z. Calcium hydroxide: a review. Int Dent J. 2005;55(5):293-301.
14- Farooq NS, Coll JA, Kuwabara A, Shelton P. Success rates of formocresol pulpotomy and indirect pulp therapy in the treatment of deep dentinal caries in primary teeth. Pediatr Dent. 2000;22(4):278-86.

15- Forsten L, Karjalainen S. Effect of a $\mathrm{Ca}(\mathrm{OH})$, solution and a chlorhexidine based detergent on the microbial activity of human carious teeth. Acta Odontol Scand. 1977;35(6):275-80.

16- Franzon R, Casagrande L, Pinto AS, García-Godoy F, Maltz M, de Araujo FB. Clinical and radiographic evaluation of indirect pulp treatment in primary molars: 36 months follow-up. Am J Dent. 2007;20(3):189-92.

17- Jordan RE, Suzuki M. Conservative treatment of deep carious lesions. J Can Dent Assoc. 1971;37(9):337-42.

18- Leksell E, Ridell K, Cvek M, Mejare I. Pulp exposure after stepwise versus direct complete excavation of deep carious lesions in young posterior permanent teeth. Endod Dent Traumatol. 1996;12(4):192-6.

19- Maltz M, de Oliveira EF, Fontanella V, Bianchi R. A clinical, microbiologic, and radiographic study of deep caries lesions after incomplete caries removal. Quintessence Int. 2002;33(2):151-9.

20- Maltz M, Oliveira EF, Fontanella V, Carminatti G. Deep caries lesions after incomplete dentine caries removal: 40-month follow-up study. Caries Res. 2007;41(6):493-6.

21- Marchi JJ, de Araujo FB, Fröner AM, Straffon LH, Nör JE. Indirect pulp capping in the primary dentition: a 4 year follow-up study. J Clin Pediatr Dent. 2006;31(2):68-71.

22- Massler M, Pawlak J. The affected and infected pulp. Oral Surg Oral Med Oral Pathol. 1977;43(6):929-47.

23- Miyashita H, Worthington HV, Qualtrough A, Plasschaert A. Pulp management for caries in adults: maintaining pulp vitality. Cochrane Database Syst Rev. 2007;18(2):CD004484.

24- Mjor IA. Pulp-dentin biology in restorative dentistry. Part 7: The exposed pulp. Quintessence Int. 2002;33(2):113-35.

25- Oliveira EF, Carminatti G, Fontanella V, Maltz M. The monitoring of deep caries lesions after incomplete dentine caries removal: results after 14-18 months. Clin Oral Investig. 2006;10(2):134-9.

26- Pereira JC, Sene F, Hannas AR, Costa LC. Tratamento conservadores da vitalidade pulpar: Princípios biológicos e clínicos. Biodonto. 2004;2(3):870 .

27- Pinto AS, de Araújo FB, Franzon R, Figueiredo MC, Henz S, GarcíaGodoy $\mathrm{F}$, et al. Clinical and microbiological effect of calcium hydroxide protection in indirect pulp capping in primary teeth. Am J Dent. 2006;19(6):382-6

28- Ribeiro CC, Baratieri LN, Perdigão J, Baratieri NM, Ritter AV. A clinical, radiographic, and scanning electron microscopic evaluation of adhesive restorations on carious dentin in primary teeth. Quintessence Int. 1999;30(9):591-9.

29- Swift ML, Byers MR. Effect of ageing on responses of nerve fibres to pulpal inflammation in rat molars analysed by quantitative immunocytochemistry. Arch Oral Biol 1992;37(11):901-12.

30- Vij R, Coll JA, Shelton P, Farooq NS. Caries control and other variables associated with success of primary molar vital pulp therapy. Pediatr Dent. 2004;26(3):214-20.

31- Warfinge J, Rozell B, Hedström KG. Effect of calcium hydroxide treated dentin on pulpal responses. Int Endod J. 1987;20(4):183-93.

32- Wiegand A, Buchalla W, Attin T. Review on fluoride-releasing restorative materials-fluoride release and uptake characteristics, antibacterial activity and influence on caries formation. Dent Mater. 2007;23(3):343-62. 